\title{
MRI findings in patients with blunt cervical trauma having a normal level of consciousness and normal CT reports
}

\author{
Hassan Amiri', Mojtaba Chardoli ${ }^{1}$, Maryam Sarvari', Samad Shams Vahdati ${ }^{*}$, Niloufar Ghodrati ${ }^{3}$, Roshan \\ Fahimi $^{4}$
}

'Emergency Medicine Management Research Center, Iran University of Medical Sciences, Tehran, Iran

${ }^{2}$ Emergency Medicine Research Team, Tabriz University of Medical Sciences, Tabriz, Iran

${ }^{3}$ Hematology and oncology department, Alborz University of Medical Sciences, Karaj, Iran

${ }^{4}$ Emergency Department, Tabriz University of Medical Sciences, Tabriz, Iran

\author{
Received: 21 February 2019 \\ Accepted: 23 April 2019 \\ Published online: 2 May 2019 \\ *Corresponding author: \\ Samad Shams Vahdati, MD; Tel: \\ +984133352078 \\ Email: shams@tbzmed.ac.ir \\ Competing interests: None. \\ Funding information: None. \\ Citation: Amiri $\mathrm{H}$, Chardoli $\mathrm{M}$ \\ Sarvari M, Shams Vahdati S, Ghodrati \\ $\mathrm{N}$, Fahimi R. MRI findings in patients \\ with blunt cervical trauma having \\ a normal level of consciousness \\ and normal CT reports. Journal of \\ Emergency Practice and Trauma \\ 2019; 5(2): 56-60. doi: 10.15171/ \\ jept.2019.09
}

\begin{abstract}
Objective: This study investigates the possible magnetic resonance imaging (MRI) findings in patients with cervical trauma having a normal level of consciousness and normal CT reports. These patients have tenderness or an uncomfortable feeling in the traumatized area as well.

Methods: In this cross-sectional anterograde study, cases were selected among patients referred to the emergency department of Hafte Tir, Iran University of Medical Sciences from 2012 to 2014. Inclusion criteria to select cases were: age above 15, blunt neck trauma, GCS $=15$, normal CT scan reports of neck, no past medical history of cervical vertebral surgery, and no persistent neurologic lesions. In order to analyse qualitative data, chisquare test was used and for quantitative data t test was applied accordingly.

Results: Two hundred eighty patients with chief complaints of neck pain due to trauma entered our study. Among this batch, 264 of them had normal CT scan reports and MRI was done for all of them. According to the results, the maximum injury in MRI was related to intervertebral disc injury (38 cases), ligamentous edema (35 cases), and muscle edema ( 22 cases), respectively. Neck tenderness from the beginning of the accident and transient neurologic signs had a significant role in MRI results $(P<0.05)$.

Conclusion: In patients with acute cervical trauma having normal CT reports, MRI must be done in those with the average age of 45 or more, tenderness in the neck area, and in those with neurologic transient symptoms.

Keywords: Cervical Trauma, MRI, CT scan, Normal consciousness, Magnetic resonance imaging
\end{abstract}

\section{Introduction}

The most vulnerable part of the neck to get injured in blunt trauma is the cervical vertebral column. Cervical vertebral column is a very complicated system which is at the risks of different ranges of pathologies like degeneration, inflammation, infection, and trauma. Our cervical vertebral column includes the collection of vertebrae, intra vertebral discs and longitudinal ligaments. Trauma of vertebral column can occur with or without neurological injuries. Neurological injuries are categorised based on physical examinations. It is called incomplete when some amount of sensory and mobility functions are detected in the body and extremities, and it is complete, if we are not able to detect any sensory or mobility functions below the level of lesion $(1,2)$.
Patients with a complete loss of neurological functions for more than 24 hours after injury are less likely to regain the function on the area of lesion. Due to the complicated biomechanical cervical vertebral system, there is a high probability of occurrence of injury patterns by trauma. Mechanical approaches simplify understanding of injury patterns because there are only very few forces that have the power to affect the spine. Although these forces are explained separately, but they usually happen altogether. Early diagnosis and correct management of cervical vertebral injury are very important because any delay or lack of diagnosis or wrong management in unstable patients, could lead to high morbidity and even high mortality. Although normal clinical findings in patients with normal level of consciousness can rule out cervical 
vertebral column injury, however it is possible that up to $10 \%$ of patients with low level of consciousness due to brain injuries experience cervical vertebral trauma $(3,4)$. In trauma patients, emergency physicians can evaluate abdomen and chest by bedside ultrasonography simply; but it is so difficult to evaluate vertebrae by bedside modalities $(5,6)$

The first step in order to take care of these patients is the use of a neck brace until physical examination and clinical findings of radiology reports show normal findings. Using a neck brace for more than 5 days might lead to pressure and injuries. In this regard, there is a need for a rapid and effective method to rule out cervical vertebral injuries in traumatic patients (7).

In recent years, magnetic resonance imaging (MRI) with high sensitivity plays an important role in the diagnosis of cervical ligaments and disc injuries. MRI is used for patients with neurologic signs and symptoms related to trauma, even if CT scan results are normal. MRI is usually applied when there are signs of fractures, malalignment or pre-vertebral inflammation or any evidence of vertebral defect in CT scan. In some studies, indications of MRI after normal CT report have been investigated and evaluated. According to these studies, there is no definitive evidence about the indication of MRI in patients with normal CT scan reports but positive symptom findings (8-20).

In the current study, we investigated the possible MRI findings in patients with cervical trauma having a normal level of consciousness and normal CT reports.

\section{Methods}

In this cross-sectional anterograde study, cases were selected among patients referred to the emergency department from 2012 to 2014. Standards of the selected cases were: age above 15 , blunt neck trauma, GCS $=15$, normal CT scan reports of neck, no past medical history of cervical vertebral surgery, and no persistent neurologic lesions.

We used convenience sampling and all patients with the above-mentioned criteria were selected. Physical examination was done by an emergency medicine resident at the arrival time and a complete history was taken. Then 64 slices of the CT scan from the base of skull up to T5 was evaluated. Images were evaluated based on acute trauma and neck spondylosis by a chief resident of radiology. Neck spondylosis was categorized in terms of mild (no slimming disc, osteophyte more than $2 \mathrm{~mm}$, no canal stenosis), moderate (obvious slimming disc, osteophyte more than $2 \mathrm{~mm}$, central or lateral canal stenosis), and sever (no complete height of disc, with or without vacuum phenomenon, osteophyte more than $2 \mathrm{~mm}$, significant canal stenosis) cases.

Data were analysed using SPSS software version 18. Frequency and central statistical indicators like the average or dispersion indicators like standard deviation were detected. In order to investigate the relationship between qualitative data, chi-square test was used and for quantitative data $t$ test was applied accordingly.

\section{Results}

Two hundred eighty patients with chief complaints of neck pain due to trauma were referred to our emergency department. Among this batch, 264 of them had normal CT scan reports and MRI was done for all of them. All necessary data and required demographic information were gathered. These included age, sex, mechanism of injury, tenderness on neck at the accident scene, concurrent head trauma, low level of consciousness, transient neurologic symptoms, injuries in the whole body, and therapeutic interventions. Once the patients were transferred to the treatment centre, the first step was conducting physical examinations and then X-rays as well as a CT scans of cervical vertebral column were requested for all patients. Seven patients out of 264 (2.7\%) had a noticeable spondylosis, which was important for patient evaluation. Surgery was done on 7 cases due to traumatic injuries on cervical vertebral area. The average age of patients in this study was 36.38 years with a standard deviation of 16.76. The minimum and maximum ages were 16 and 88 years, respectively. Among 264 participating patients, 141 (53.4\%) had a motor vehicle accident and 60 of them (22.7\%) were injured by a falling trauma (table 1). Midline neck tenderness with $92.8 \%$ and head trauma with $66.3 \%$ were the most common signs and symptoms of patients. There was a statistically significant difference between patients who had surgery and those with transient neurologic symptoms $(P<0.000)$ (Table 2$)$. MRI results in 74 cases (28\%) were positive whereas, in 190 cases $(72 \%)$, there was no sign of acute trauma in the MRI (Table 3).

According to the results of our study we found out that the maximum injury in MRI was related to intervertebral disc injury (38 cases), ligamentous edema (35 cases), and muscle edema (22 cases), respectively (Table 3 ).

Demographic variables and mechanism of injury based on positive or negative MRI results were compared and analyzed (Table 1).

The average age of patients with positive MRI results was significantly more than others $(P<0.000)$, whereas there were no statistically significant changes due to the mechanism of injury and sex.

Patients' clinical signs and symptoms based on positive or negative MRI results were compared and analyzed (Table 2).

Neck tenderness from the beginning of the accident and transient neurologic signs had a significant role in MRI results $(P<0.05)$.

\section{Discussion}

MRI is a highly sensitive and specific method for the diagnosis of acute and chronic vertebral column injury $(10,11)$. This technique can make a clear image of the 
Table 1. Frequency distribution, demographic variables and mechanism of injury based on positive or negative MRI findings

\begin{tabular}{|c|c|c|c|c|}
\hline & \multirow{2}{*}{$\begin{array}{l}\text { Demographic variables and } \\
\text { mechanism of injury }\end{array}$} & \multicolumn{2}{|c|}{ MRI results } & \multirow{2}{*}{$\begin{array}{l}\text { Statistical analysis: } \\
\text { Chi-square and t test }\end{array}$} \\
\hline & & Positive ( 74 cases) & Negative (190 cases) & \\
\hline \multicolumn{2}{|c|}{ Age (M $\pm S D)$ (264 cases) (year) } & $42.76 \pm 17.00$ & $34 / 57 \pm 16.14$ & $P<0.000$ \\
\hline \multirow{2}{*}{ Sex } & Male (177 case) $(67.1 \%)$ & $46(26.0)$ & $131(74.0)$ & \multirow[t]{2}{*}{$P<0.292$} \\
\hline & Female (87 cases) $(32.9 \%)$ & $28(32.2)$ & $59(67.8)$ & \\
\hline \multirow{6}{*}{$\begin{array}{l}\text { Mechanism of } \\
\text { injury }\end{array}$} & Vehicle accident (141 cases) (53.4\%) & $37(26.2)$ & $104(73.8)$ & \multirow[t]{6}{*}{$P<0.422$} \\
\hline & Physical education ( 2 cases) $(0.7 \%)$ & $0(0.0)$ & $2(100.0)$ & \\
\hline & Falling (60 cases) $(22.7 \%)$ & $20(33.3)$ & $40(66.7)$ & \\
\hline & Pedestrian (31 cases) (11.8\%) & $8(25.8)$ & $23(74 / 2)$ & \\
\hline & Beating (10 cases) (3.8\%) & $5(50.0)$ & $5(50 / 0)$ & \\
\hline & Direct trauma (20 cases) $(7.6 \%)$ & $4(20.0)$ & $16(80 / 0)$ & \\
\hline
\end{tabular}

Table 2. Frequency, clinical signs and symptoms based on positive or negative MRI findings

\begin{tabular}{|c|c|c|c|}
\hline \multirow{2}{*}{ Clinical signs } & \multicolumn{2}{|c|}{ MRI results } & \multirow{2}{*}{$\begin{array}{c}\text { Statistical analysis } \\
\text { Chi-square test }\end{array}$} \\
\hline & Positive (74 cases) $(\%)$ & Negative (190 cases) (\%) & \\
\hline Neck tenderness from the beginning of trauma & $23(31.1)$ & $90(47.4)$ & $P<0.016$ \\
\hline Head trauma & $50(67.6)$ & $125(65.8)$ & $P<0.784$ \\
\hline Loss of consciousness & $21(28.4)$ & $60(31.6)$ & $P<0.613$ \\
\hline Neck midline tenderness & $67(90.5)$ & $178(93.7)$ & $P<0.375$ \\
\hline Transient neurologic signs & $11(14.9)$ & $8(4.2)$ & $P<0.003$ \\
\hline Injury in other parts of the body & $30(40.5)$ & $70(36.8)$ & $P<0.578$ \\
\hline Spondylitis & $2(2.7)$ & $5(2.6)$ & $P<0.974$ \\
\hline
\end{tabular}

Table 3. Frequency and relative frequency of acute trauma in neck MRI results and type of trauma in patients

\begin{tabular}{|c|c|c|c|}
\hline & Existence of acute trauma in MRI results & Relative frequency & Frequency \\
\hline \multirow{9}{*}{ Acute trauma ( 74 cases) } & No sign of acute trauma (190 cases) & 72 & 190 \\
\hline & Spinal injury & 0 & 0 \\
\hline & Intervertebral disc injury & 51.35 & 38 \\
\hline & Single-column injury & 5.4 & 4 \\
\hline & Two-column injury & 1.35 & 1 \\
\hline & Three-column injury & 0 & 0 \\
\hline & Muscle edema & 29.72 & 22 \\
\hline & Ligamentous Edema & 47.29 & 35 \\
\hline & Epidural hematoma & 1.35 & 1 \\
\hline
\end{tabular}

spinal cord and nerve root integrity and plays an important role in the diagnosis of intervertebral disc injuries, soft tissue, ligament and vertebral arteries. Despite the high sensitivity of MRI in the diagnosis of soft tissue injuries, there are some limitations. High frequency of false positive results up to $40 \%$ in some studies is an obvious example of these limitations. Another problem is related to the delay in performing MRI. MRI is requested to differentiate soft tissue and vertebral column injuries. At the time of doing MRI, patients who have been immobilized for a long period of time might have some problems especially those with a low level of consciousness (10-20). In our study in 74 patients (28\%), MRI results were positive. One of the very important findings in our study was the significant age difference among patients with positive MRI. The average age of patients with positive MRI was higher than those with negative MRI results. It seems that the probability of injury increases by getting older even with negative CT scan reports, but for correct conclusion extensive studies are needed. Cervical vertebral column MRI in patients with negative CT reports has been investigated in many studies. In Ackland et al's study, patients with cervical midline tenderness and pain due to trauma were referred to the trauma centre and evaluated by cervical vertebral CT. In a 2 -year period, MRI was requested for 178 patients with negative CT results. Thirty eight cases had soft tissue injuries and surgery was done for 5 cases (14). In our study, surgery was done for 8 cases after obtaining MRI results, which is similar to the study conducted by Ackland et al. Also, in patients with expression of pain disorders, a decreased level of consciousness and simple radiography with no fracture or lesion in cervical vertebral CT, selective 
diagnostic method is preferred. There are two methods in approaching patients with the neck trauma:

1. Multi detector CT scan: in this method, normal results can rule out cervical vertebral injury. It is requested when there is simple ligament lesion, or not any available MRI modality, and when we have a professional radiologist.

2. Cervical MRI: It is requested to rule out soft tissue lesions even with negative $\mathrm{CT}$ reports.

According to the American College of Surgeon for Trauma, there is no sufficient evidence concerning the evaluation method in traumatic patients with cervical vertebral injuries and normal CT reports (21).

Several studies showed that cervical ligament injuries in unconscious trauma patients could not be detected unless with MRI. In a meta-analysis by Schoenfeld et al, findings revealed that cervical MRI played an important role in the diagnosis of 182 cases with cervical vertebral injuries. MRI findings led to a change of the treatment plan in 96 cases. In this study, there were 1550 patients with normal CT scan results. Since there are not any studies comparing CT scan and MRI results with only CT scan, we cannot detect the gold standard for measuring the accuracy and correct interpretation of radiologists for CT scans or MRI findings. Determining the vertebral column instability and those cases that need sugary are still controversial. Technology improvement, sensitivity and speciality of CT scan have made a significant progression in this regard (15). Other researchers like Hogan believe that cervical vertebral CT scan has good sensitivity and specificity for detecting unstable bone tissue or ligament (12). In this meta-analysis, researchers showed that normal cervical vertebral CT can rule out any lesion leading to the instability of vertebral column. In our study, MRI reports showed 4 cases of stable ligament injury and 7 cases of spinal cord contusion (12). In another meta-analysis by Panczykowski et al, 17 eligible studies included 14327 patients. The sensitivity and specificity of multi-slice helical CT scan for the diagnosis of unstable acute injury of cervical vertebral column was detected higher than $99.9 \%$. They concluded that only modern CT scan for the diagnosis of cervical vertebral column instability is sufficient (20). In our study, another separate investigation was done on patients who had surgery. Four cases out of 8 (50\%) had transient neurological symptoms in physical examination, whereas $5.9 \%$ of them, with positive physical examination, had transient neurologic symptoms. intervertebral disc injury was reported in all patients. Although there are some advantages concerning MRI and its high power of diagnosis, some disadvantages exist. They include the probable risk of longer waiting time to do MRI, difficult monitoring and resuscitation in the MRI imaging centre $(10,22)$, and possible extra costs for patients with negative CT reports. Since it is very difficult for patients to wear a hard cervical collar and it might lead to sores in occipital area in low conscious patients, patients' triage must be done within 48 hours of trauma in order to prevent other problems if strict immobilization is needed $(10,23)$.

\section{Conclusion}

In conclusion, age, neck tenderness, and transient neurologic symptoms can be factors in the prediction of positive findings for MRI in traumatic patients with normal CT. On the other hand, in patients with acute cervical trauma having normal CT reports, MRI must be done in those with the average age of 45 or more, tenderness in the neck area, and in those with neurologic transient symptoms.

\section{Ethical issues}

Ethics committee approval was granted for this study from the ethics committee of Tabriz University of medical sciences. (Ethics No. 91/D/130/1085). Subjects were enrolled in the study after obtaining voluntary informed consent according to the Declaration of Helsinki.

\section{Authors' contributions}

Concept: HA, MC, MS. Critical reviews: SSV. Data collection: NG. Writing: RF.

\section{References}

1. Snell RS, Smith MS. Clinical Anatomy for Emergency Medicine. 1st ed. St. Louis: Mosby; 1993.

2. Sabiston DC. Neurosurgery. In: Textbook of Surgery: The Biological Basis of Modern Surgical Practice. 20th ed. Elsevier; 2016.

3. van den Berg ME, Castellote JM, Mahillo-Fernandez I, de Pedro-Cuesta J. Incidence of spinal cord injury worldwide: a systematic review. Neuroepidemiology 2010; 34(3): 18492. doi: 10.1159/000279335.

4. Geisler FH, Coleman WP, Grieco G, Poonian D. Recruitment and early treatment in a multicenter study of acute spinal cord injury. Spine (Phila Pa 1976) 2001; 26(24 Suppl): S58-67.

5. Ojaghi Haghighi SH, Adimi I, Shams Vahdati S, Sarkhoshi Khiavi R. Ultrasonographic diagnosis of suspected hemopneumothorax in trauma patients. Trauma Mon 2014; 19(4): e17498. doi: 10.5812/traumamon.17498.

6. Tajoddini S, Shams Vahdati S. Ultrasonographic diagnosis of abdominal free fluid: accuracy comparison of emergency physicians and radiologists. Eur J Trauma Emerg Surg 2013; 39(1): 9-13. doi: 10.1007/s00068-012-0219-5.

7. Ala A, Shams Vahdati S, Taghizadieh A, Miri SH, Kazemi N, Hodjati SR, et al. Cervical collar effect on pulmonary volumes in patients with trauma. Eur J Trauma Emerg Surg 2016; 42(5): 657-60. doi: 10.1007/s00068-015-0565-1.

8. Saltzherr TP, Fung Kon Jin PH, Beenen LF, Vandertop WP, Goslings JC. Diagnostic imaging of cervical spine injuries following blunt trauma: a review of the literature and practical guideline. Injury 2009; 40(8): 795-800. doi: 10.1016/j.injury.2009.01.015.

9. Hoffman JR, Mower WR, Wolfson AB, Todd KH, Zucker MI. Validity of a set of clinical criteria to rule out injury to the cervical spine in patients with blunt trauma. National Emergency X-Radiography Utilization Study 
Group. N Engl J Med 2000; 343(2): 94-9. doi: 10.1056/ nejm200007133430203.

10. Dunham CM, Brocker BP, Collier BD, Gemmel DJ. Risks associated with magnetic resonance imaging and cervical collar in comatose, blunt trauma patients with negative comprehensive cervical spine computed tomography and no apparent spinal deficit. Crit Care 2008; 12(4): R89. doi: 10.1186/cc6957.

11. Steigelman M, Lopez P, Dent D, Myers J, Corneille M, Stewart R, et al. Screening cervical spine MRI after normal cervical spine CT scans in patients in whom cervical spine injury cannot be excluded by physical examination. Am J Surg 2008; 196(6): 857-62; discussion 62-3. doi: 10.1016/j. amjsurg.2008.07.040.

12. Hogan GJ, Mirvis SE, Shanmuganathan K, Scalea TM. Exclusion of unstable cervical spine injury in obtunded patients with blunt trauma: is MR imaging needed when multi-detector row CT findings are normal? Radiology 2005; 237(1): 106-13. doi: 10.1148/radiol.2371040697.

13. Schuster R, Waxman K, Sanchez B, Becerra S, Chung R, Conner S, et al. Magnetic resonance imaging is not needed to clear cervical spines in blunt trauma patients with normal computed tomographic results and no motor deficits. Arch Surg 2005; 140(8): 762-6. doi: 10.1001/archsurg.140.8.762.

14. Ackland HM, Cameron PA, Varma DK, Fitt GJ, Cooper DJ, Wolfe R, et al. Cervical spine magnetic resonance imaging in alert, neurologically intact trauma patients with persistent midline tenderness and negative computed tomography results. Ann Emerg Med 2011; 58(6): 521-30. doi: 10.1016/j.annemergmed.2011.06.008.

15. Schoenfeld AJ, Bono CM, McGuire KJ, Warholic N, Harris MB. Computed tomography alone versus computed tomography and magnetic resonance imaging in the identification of occult injuries to the cervical spine: a meta-analysis. J Trauma 2010; 68(1): 109-13; discussion 134. doi: 10.1097/TA.0b013e3181c0b67a.

16. Holmes JF, Mirvis SE, Panacek EA, Hoffman JR, Mower
WR, Velmahos GC. Variability in computed tomography and magnetic resonance imaging in patients with cervical spine injuries. J Trauma 2002; 53(3): 524-9. doi: 10.1097/01. ta.0000026405.09344.11.

17. Cohen WA, Giauque AP, Hallam DK, Linnau KF, Mann FA. Evidence-based approach to use of MR imaging in acute spinal trauma. Eur J Radiol 2003; 48(1): 49-60.

18. Plumb JO, Morris CG. Clinical review: Spinal imaging for the adult obtunded blunt trauma patient: update from 2004. Intensive Care Med 2012; 38(5): 752-71. doi: 10.1007/ s00134-012-2485-4.

19. Menaker J, Philp A, Boswell S, Scalea TM. Computed tomography alone for cervical spine clearance in the unreliable patient--are we there yet? J Trauma 2008; 64(4): 898-903; discussion -4. doi: 10.1097/TA.0b013e3181674675.

20. Panczykowski DM, Tomycz ND, Okonkwo DO. Comparative effectiveness of using computed tomography alone to exclude cervical spine injuries in obtunded or intubated patients: meta-analysis of 14,327 patients with blunt trauma. J Neurosurg 2011; 115(3): 541-9. doi: 10.3171/2011.4.jns101672.

21. Tewari MK, Gifti DS, Singh P, Khosla VK, Mathuriya SN, Gupta SK, et al. Diagnosis and prognostication of adult spinal cord injury without radiographic abnormality using magnetic resonance imaging: analysis of 40 patients. Surg Neurol 2005; 63(3): 204-9. doi: 10.1016/j. surneu.2004.05.042.

22. Como JJ, Thompson MA, Anderson JS, Shah RR, Claridge JA, Yowler CJ, et al. Is magnetic resonance imaging essential in clearing the cervical spine in obtunded patients with blunt trauma? J Trauma 2007; 63(3): 544-9. doi: 10.1097/ TA.0b013e31812e51ae.

23. Greenbaum J, Walters N, Levy PD. An evidenced-based approach to radiographic assessment of cervical spine injuries in the emergency department. J Emerg Med 2009; 36(1): 64-71. doi: 10.1016/j.jemermed.2008.01.014. 